\title{
Forest carbon offsets over a smart ledger
}

\author{
Grammateia Kotsialou* \\ g.m.kotsialou@lse.ac.uk \\ Karlygash Kuralbayeva ${ }^{\dagger}$ \\ karlygash.kuralbayeva@kcl.ac.uk
}

\author{
Timothy Laing ${ }^{\ddagger}$ \\ T. J . Laing@brighton. ac.uk
}

October 17, 2021

\begin{abstract}
2021 has seen increasing climate policy action and net-zero commitments by individuals, companies and governments. A crucial aspect for the transition to net-zero is the voluntary offset market, with projects relating to REDD+ amongst the most popular. Policy-makers are grappling to make such markets efficient and scalable, however, many issues undermine these efforts pertaining to additionality, permanence, leakage and property and community rights. Digitisation has also accelerated, with technologies, notably blockchain, starting to enter the climate change space. Its use is becoming increasingly common within the voluntary market and, in particular, REDD+, although such projects, are generally in proposal or pilot stages. Given the emergence of other technologies such as AI and machine learning, the technologisation of REDD+ is only likely to increase. Thus modern technologies are being seen by developers as a potential solution to issues hindering REDD+. Potential benefits arising from technology use are unlikely to fully accrue without a wider focus on what has undermined REDD+ to date. As such, there is an urgency to establish an understanding of how projects can utilise these technologies to reduce long-standing issues. To do this, we discuss these issues together with technologies' capacity to address drawbacks of REDD+ projects.
\end{abstract}

\section{Introduction}

Over the past decade, financial regulators, business leaders, governments and individuals around the world have recognised the urgency of the climate change challenge, leading to a growing net zero 'club' of countries (e.g., the UK UK, 2021, the EU [EU, 2019, the US [US, 2021]) and companies (e.g., Facebook Facebook, 2019, Google Google, 2020, BP [BP, 2020, Nestle Nestle, 2019]). Elsewhere, central banks and financial regulators are discussing how to drive the transition to net-zero financial

\footnotetext{
${ }^{*}$ London School of Economics and Political Science: Department of Mathematics

${ }^{\dagger}$ King's College London: Department of Political Economy

${ }^{\ddagger}$ Corresponding Author: University of Brighton: School of Business and Law, Centre for Change, Entrepreneurship and Innovation Management
} 
systems NGFS, 2021 with the new $\$ 70$ tn Glasgow Financial Alliance for Net Zero initiative (GFANZ), launched in April 2021, marking a watershed moment for the banking industry by bringing together leading net-zero initiatives from across the financial system [UNFCC, 2021]. This aims to mobilise and direct much needed capital to back up sustainable portfolios and finance investment into new technologies, helping to achieve the goals of the Paris Agreement.

Mitigation pathways to net-zero emissions require a wide portfolio of decarbonization technologies, ranging from the established such as renewables, to emerging such as inert anodes for aluminium to negative emission technologies such as afforestation and reforestation, bioenergy with carbon capture and storage (BECCS), and direct air capture Rogelj et al., 2018. Emerging technologies are needed to decarbonise heavy industrial sectors like cement and steel, which generate nearly $20 \%$ of global $\mathrm{CO} 2$ emissions, but for which switching fuel sources is not a viable option for achieving net-zero de Pee et al., 2018. However, few such emerging technologies are yet available at commercial scale with significant further investment required. This creates a time-lag between commitments to mitigate emissions and the availability of technologies. Instead, such industries will need to use carbon offsets: credits for sequestering carbon or reducing emissions, offered by voluntary carbon markets to meet net zero targets before suitable technologies can be employed [McKinsey, 2020. Amongst the different types of carbon offsets forestry activities are perhaps the most mature and readily available, with activities such as afforestation and avoided deforestation historically being regarded as viable and cost-effective options to address climate change Eliasch, 2012.

This drive to net-zero, along with the large sums of money increasingly being mandated to meet the challenge, brings increased attention to the voluntary markets that will supply these offsets. In November 2020, the Taskforce on Scaling Voluntary Carbon Markets (TSVCM) released recommendations to improve the current state of the voluntary carbon trade and promote it as a system to offset and reduce carbon emissions [TSVCM, 2020b], based on a projected 15-fold scale-up in carbon offsetting by 2030 TSVCM, 2020a. The history of the voluntary market, inclusive of the market for forestry-related offsets via Reducing Emissions from Deforestation and Forest Degradation (REDD+) has however been beset by a number of limiting factors such as questions relating to transparency, additionality, permanence and credibility. Into this mix has come Covid-19 and an acceleration of digitisation McKinsey, 2020. Digital technologies, including chatbots, the IoT (the 'internet of things'), artificial intelligence (AI), big data and distributed ledger technologies (DLT) such as blockchain are mushrooming in financial services, shipping and supply chain management BiTA, 2017, proxy voting and elections Broadbridge, 2018. Notably blockchain has also started to enter the climate change space, especially in relation to the integration of variable renewable energy (VRE) into power systems IRENA, 2019, Metelitsa, 2018. Such digital technologies are also entering the world of carbon offsets Hartmann and Thomas, 2020, Chen, 2018, along with forest monitoring and sustainable supply chains, raising the question of whether it can help to overcome challenges that have hampered REDD+ projects, and if so how it can best be used to overcome these barriers.

This paper examines these questions by assessing the extent to which blockchain can help in addressing key concerns related to REDD+ projects. The paper builds and extends nascent literature that highlights the use of blockchain in climate change [Howson, 2019 and REDD+ Howson et al., 2019. We contribute to the emerging literature by examining specific critical issues that have generally hindered the voluntary carbon market and REDD+ specifically and we analyse how blockchain has, 
Figure 1: Annual Voluntary Carbon Offset Issuances and Retirements, 2005-2020

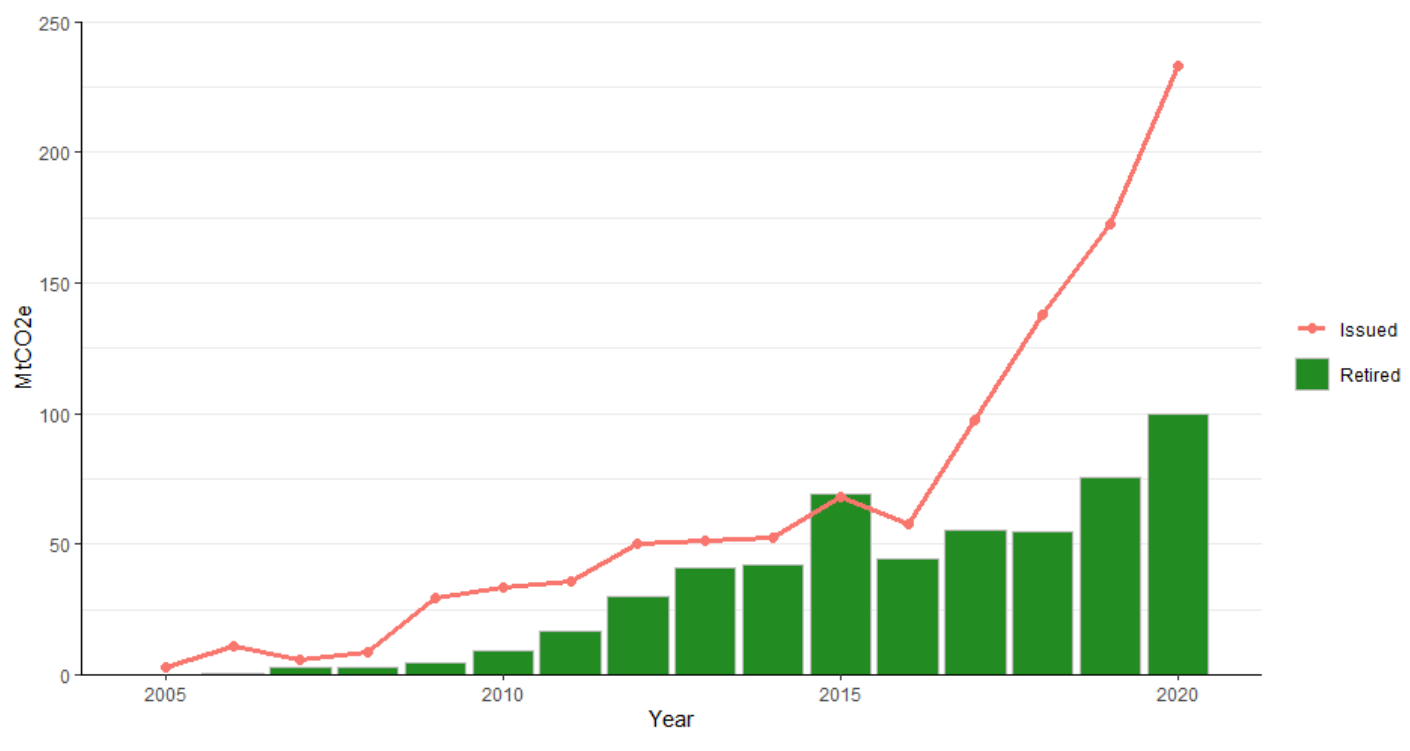

Source: Ecosystem MarketPlace, 2021

could, or may not be able to, help solve these issues. First, we revisit the experience of voluntary carbon markets and the role of forest activities within these markets. Second, we discuss how modern technologies such as blockchain could help in addressing long-standing challenges of forest carbon offsets including measurement, monitoring and enforcement, as well as financial transparency and high transaction costs. Third, we argue that blockchain-led technologies offer new benefits to both buyers and sellers of forestry offset projects, potentially expanding the reach and scope of voluntary carbon markets. Finally, we discuss pathways forward for the use of blockchain in REDD+ and related areas, and present open questions for further research.

\section{Voluntary market: Growth, Issues and Opportunities}

Carbon offsets operate in both compliance and voluntary markets. The former are subject to tight regulation and supervision by national governments and international bodies. In contrast, voluntary markets are not defined by specific caps and firms are free to choose whether, and in which projects, they wish to invest. The voluntary market as a whole, however, has been relatively small for most of its history, but has started to grow rapidly in recent years driven by company commitments and anticipation of future regulation (Figure 1). The voluntary carbon offset market is expected to grow to $\$ 100$ billion by 2030 up from $\$ 300$ million in 2018 Shankleman and Rathi, 2021 as firms committing to net-zero targets, but without the internal ability (or will) to reduce emissions directly within their supply chain race to purchase offsets. For some sectors, such as aluminium, offsetting is the only credible pathway to net-zero giving the existing technology.

This surge in interest in voluntary carbon markets is matched by a surge in interest in the development of sustainable supply chains - especially relating to agricultural commodities. Net-zero targets (and sustainable supply-chains) met through offsetting are credible only so as far as the offset credits 
involved are valid, permanent and additional. Determining this requires transparency over the nature of the project, its performance and continuing impact. Should doubts arise over any of the factors then the offsets involved will lose credibility - and in turn commitment to net-zero is undermined. What is therefore required is transparency over voluntary offsets, both for the companies purchasing these offsets and also for stakeholders (including shareholders) monitoring net-zero targets. This transparency will in turn bring credibility to offsets and net-zero targets - helping to boost demand for offset projects, including REDD+, and helping companies and countries meet ambitious goals.

\section{Forest carbon offsets within voluntary carbon markets}

Different forestry activities that are feasible for carbon offsets include afforestation (planting trees on open sites), reforestation (planting trees on recently cleared sites), improved forest management, avoided deforestation and forest degradation and are grouped together into the general basket of REDD +. REDD + initiatives are generally conceived within the Payment for Environmental Service (PES) framework with communities remunerated for activities related to preserving or enhancing ecosystems, but without an explicit requirement to sell carbon credits Nation, 2021. In practice, REDD + has bifurcated into two streams: $(i)$ national or jurisdictional programs (such as those in Guyana, Gabon and Brazil), which are mainly funded by multilateral or bilateral donors (where finance is used to change broad policy frameworks and institute smaller projects) and (ii) projectlevel activity in smaller areas, local communities and farms. These two scales have emerged in order to tackle different aspects of reducing deforestation, and to leverage different sources of finance. It is the latter, sub-national projects, that is predominantly the focus of the carbon offsets market - and thus the scope of this paper.

Forest and other land use projects have historically played a much larger role in voluntary than compliance markets. Forestry activities accounted for $38 \%$, or almost $41.5 \mathrm{MtCO}_{2}$ e of all carbon offset projects in 2019, with avoided unplanned deforestation initiatives alone accounting for more than 22 $\mathrm{MtCO}_{2} \mathrm{e}$ (Figure 2).

Despite accounting for a large share of the voluntary market, forestry carbon offsets have faced a number of challenges pertaining to verifiability, permanence, additionality and leakage A Angelsen, 2010, as well as insufficient financial transparency, vague and expensive standards Laing et al., 2016 and high transaction fees Nantongo and Vatn, 2019. Next, we examine how the use of blockchain within forestry offset projects could help to solve some of the most challenging of these issues.

\section{Modern technologies in forestry carbon projects}

The integration between carbon markets and blockchain technology has already begun. The number of forestry projects utilising blockchain technology, even though still in proposal and pilot stages, is increasing (Figure 3). This trend is unsurprising as the technology enables a decentralized communication and cooperation between multiple unknown parties, by building an infrastructure which allows peers to safely share, validate and immutably store information. Applying this solution to carbon markets could provide a transparent digital means for an automated decentralised verification process of issuing, monitoring and even revoking carbon credits, which could boost demand and reduce issues 
Figure 2: Top 10 Project Types by Volume and Price: Voluntary Carbon Credits, 2019

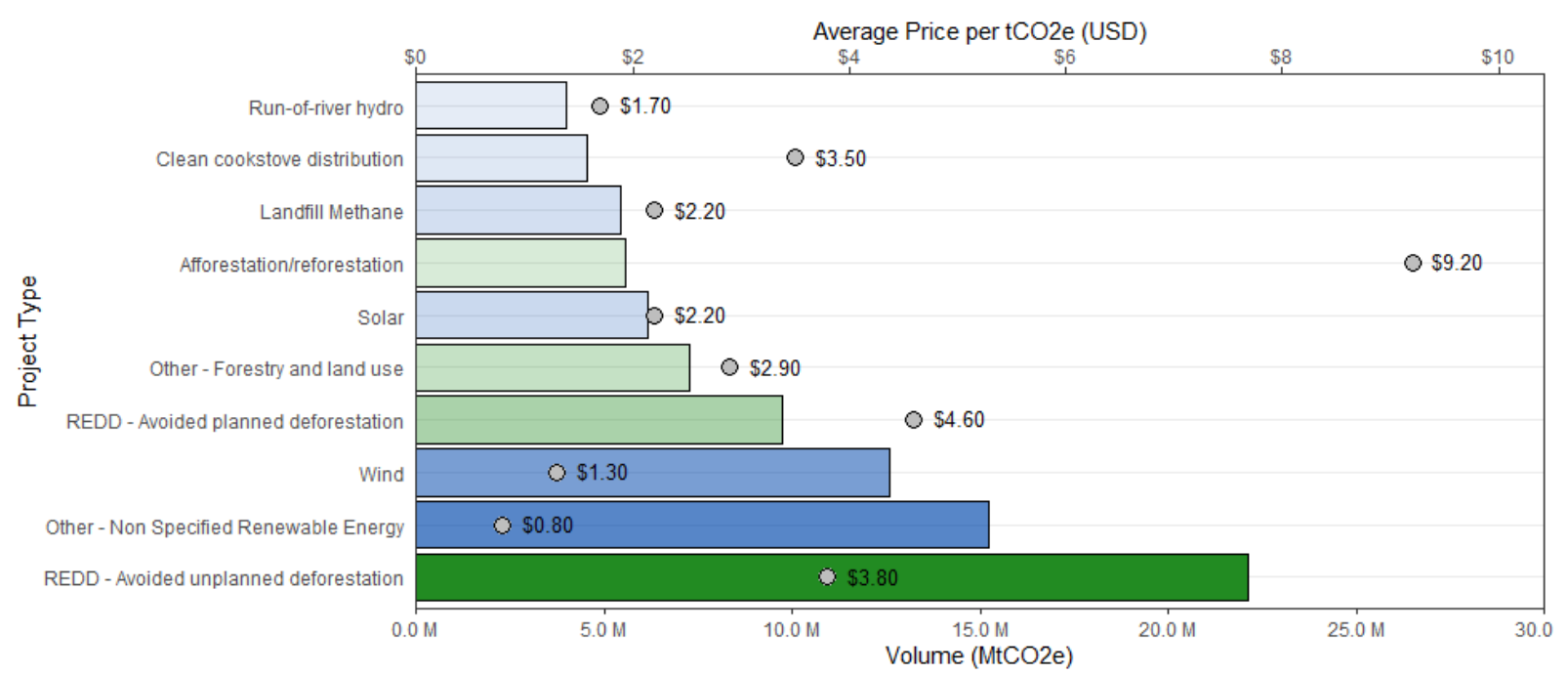

Source: Ecosystem MarketPlace, 2021

in relation to transactions, verifiability, permanence and leakage.

But what is blockchain, and how can it be finely integrated into carbon offsets? Blockchain is an immutable distributed ledger of all the transaction data occurring within a system. Systems powered with blockchain technology consist of an interconnected network of computers (see Figure $5(a)$ in Appendix) that interact with each other for the exchange and storage of transaction information. Importantly, blockchain technology is still developing, and performance, scalability and energy requirements continue to improve with time. Carbon offsets work by generating emissions 'savings' through positive activities, such as planting trees or saving forests. These savings are then sold to willing buyers creating a carbon trading market, which uses carbon credits as its native 'currency'. Credits can represent either a value (e.g. a currency), a permit (e.g. allowance to emit one tonne of carbon dioxide) or even ownership of an asset (e.g. ownership of a particular tree). With the use of blockchain in this market the information of what type of asset a credit represents is added to the users' blockchain accounts (wallets) in the form of small pieces of data, known as tokens (Figure 4). These tokens can then be sold on to other users, creating a carbon market. The value of each token depends on the underlying asset, e.g. how large the emissions savings are generated from the asset. Using blockchain can transparently process and securely store every token transaction. In addition, a wide range of information pertaining to the underlying asset (emissions, legal status, or associated environmental and social performance) can follow the token from the seller to the buyer - and be updated as the status of the asset changes. All initiatives in Figure 3 adopt this general underlying idea of integrating carbon markets with blockchain, however, each of them seems to follow the verification standards of issuing credits of their own selected third-party verifier, hence token values may vary across regions covered by different projects. 
Figure 3: Blockchain-led Carbon Credit Project Initiatives

\begin{tabular}{|l|c|l|r|}
\hline Project & Status & Forestry aCtivity & REGION \\
\hline GainForest, 2019 & Pilot/In development & Avoided deforestation & Global \\
\hline
\end{tabular}

Sustainable preservation by unifying: accessible automated monitoring (using machine learning, satellites, drones), auditable decentralised payments (using a smart contract), stakeholder engagement and user-focused token incentives.

\begin{tabular}{|l|l|l|l|}
\hline Treecycle, 2019 & Pilot/In development & Reforestation & Paraguay \\
\hline
\end{tabular}

Major eucalyptus reforestation project providing local population with employment, energy and timber. Token holders get $40 \%$ net profit share over a 22-year investment cycle. All (ownership) rights are transferable upon sale of tokens.

\begin{tabular}{|l|l|l|l|}
\hline Veridium, 2016 & Pilot/In development & Avoided deforestation & Global \\
\hline
\end{tabular}

Tokenise natural assets (carbon, biodiversity, water and social impact offsets) onto blockchain, integrate tokens into supply chain management systems to transparently monitor movement of global products, know your carbon footprint.

\begin{tabular}{|l|l|l|l|}
\hline Regen Network, 2018 & Launched & Avoided deforestation & Ecuador, California \\
\hline
\end{tabular}

Dealing with data quality and land tenure with decentralised monitoring of ecological state, generate fungible or non-fungible tokens which represent agreements based on claims (made through smart contracts) about the state.

\begin{tabular}{|l|l|l|l|}
\hline Universal Carbon, 2019 & Launched & Avoided deforestation & Congo, Kenya \\
\hline
\end{tabular}

Democratising access to carbon credits, each token represents one year tonne of CO2 averted by preventing rainforest loss or degradation. You can burn tokens (to offset your carbon footprint), buy/sell or hold as an invenstment.

\begin{tabular}{|l|l|l|l|}
\hline Carbon Credit Token, 2020 & Launched & Avoided deforestation & Amazon \\
\hline
\end{tabular}

Development of a carbon credit market by assigning value to GHG emissions, penalise those who emit more than threshold and reward those who emit less. Each token will be issued with neutral carbon footprint.

\begin{tabular}{|l|c|c|c|}
\hline Vlinder, 2019 & Launched & Blue carbon & Myanmar, Global \\
\hline
\end{tabular}

Focused on mangrove coastal ecosystems, carbon credits are purchased from trusted sellers/buyers at an automated auction, tokenising each $\mathrm{CO} 2$ tonne, engaging local communities and developing AI to remote track forests.

\begin{tabular}{|c|c|c|c|}
\hline Nori, 2017 & Launched & Afforestation & USA \\
\hline \multicolumn{4}{|c|}{$\begin{array}{l}\text { Calculate your carbon footprint and remove it, dealing with issues of double counting and fraud } \\
\text { in existing markets, buying one token removes and stores one CO2 tonne for ten years. }\end{array}$} \\
\hline $\mid$ Grove (FSL), 2020 & In development & Mangrove forestry & India \\
\hline
\end{tabular}

Create a carbon sink of 3 billion tons by 2030, reduce monitoring costs through remote sensing and machine learning, blockchain-based smart contract ensures rewards for conservation efforts of local communities. 


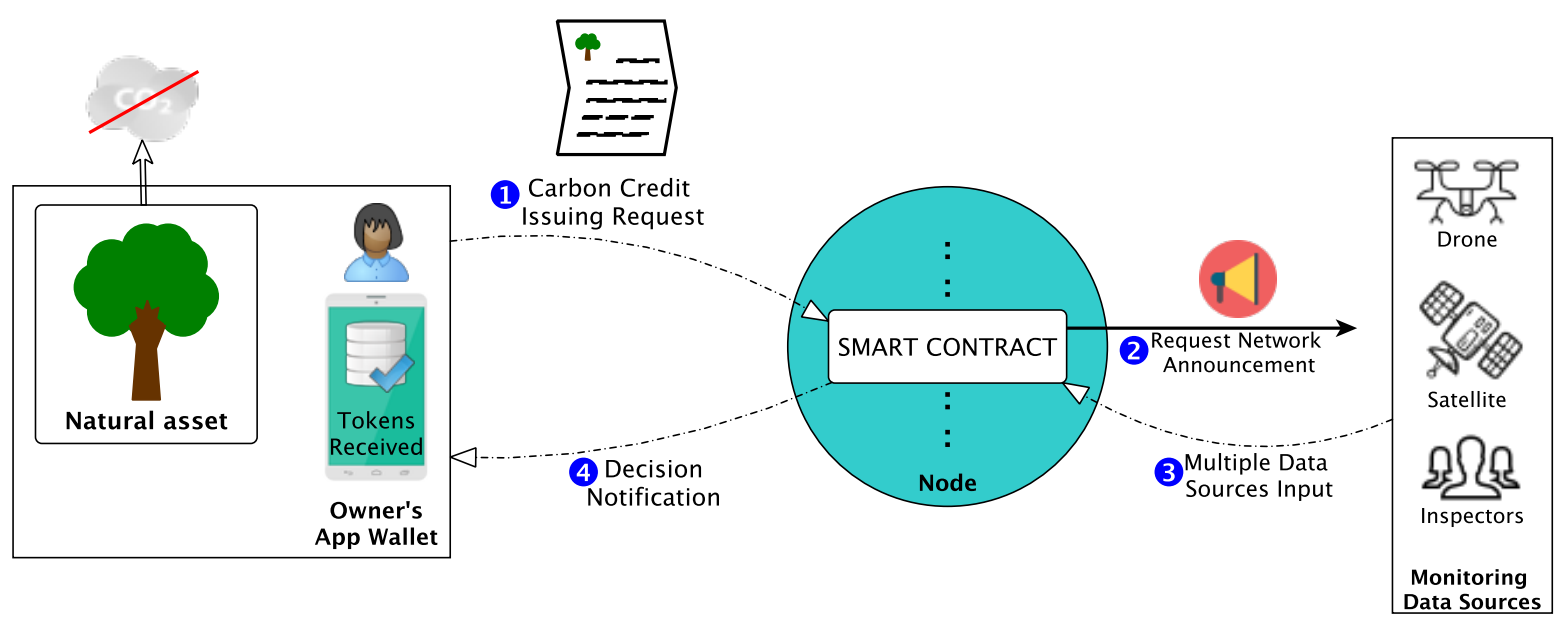

Smart contracts are deployed within transactions sent to the blockchain network, thus they are immutably stored in the ledger once confirmed. When a new transaction requires the service of a particular smart contract, lets say the Issuing Carbon Credits smart contract, the transaction calls that smart contract's function and gives it an input to process. For example, a tree owner submits all necessary information to request the carbon credits her tree generates. The smart contract algorithm announces this request to the network. External data sources connected to the blockchain receive this announcement and each one of them submits its own information with respect to that request. The input from all data sources is automatically evaluated by the smart contract. Global standards for issuing carbon credits can be added as conditions into the algorithms of smart contracts. If verified, tokens are issued to wallet of the owner, who can then start trading in the blockchain powered carbon market. If declined, the smart contract can return the reasons for rejection or request further information.

\section{Verifiability, financial transparency and transaction costs}

The complex, and unregulated environment of REDD+ projects makes it a potentially suitable sector for application of blockchain technology. The supply chains for REDD+ carbon credits are filled with intermediaries, conservation businesses and (inter)national organisations overseeing the (re)distribution of REDD+ funds Oberhauser, 2019. These organisations often retain administrative fees and distribute money across a range of projects. This creates both transaction costs and a disconnect between the buyer and seller of REDD+ credits. The lack of rigid financial transparency is coupled with insufficient standardisation of the voluntary carbon market and the REDD+ sector specifically. Currently, most credits are issued through unique processes that vary between different suppliers, which makes it difficult to objectively measure the quality of carbon credits circulating in the market. For this reason, there have been suggestions for voluntary markets to establish a "fungible currency" in the form of universally acceptable standards for what is being traded within them Streck, 2020. Standards have developed such as the Verified Carbon Standard (VCS) and the Gold Standard but they are far from ubiquitous in the market, and it is unclear how they will respond to rapid scales up in demand. Along with the challenges of heterogeneous approaches to measuring the quality of carbon credits, checking whether contracts are fulfilled by voluntary projects may become particularly cumbersome and can require significant finance Streck, 2020. Different approaches are developed to bring standardisation to the market, but more often than not they rely on a great amount of human labour in verifying the performance of activities. The quantity of labour involved in measuring and monitoring the scale of reforestation and afforestation, or avoided deforestation 
Oberhauser, 2019 makes supervision and implementation of such initiatives relatively expensive and increases the cost of carbon credits. The average costs of forestry-based carbon offsets exceed the costs of renewable energy projects by more than a factor of 3, partly due to the high involvement of human labour in the former (Figure 2). Moreover, more transparency is needed to ensure that carbon credits are verifiable, do not lead to "double-counting" and are not exploited by "carbon cowboys" who seek to gain rewards for supplying carbon credits of dubious origin and quality Maguire, 2011. Addressing the above limitations requires efficient and effective measurement, monitoring, enforcement and low-cost financial transactions, all potentially offered by blockchain-led projects.

Blockchain technology can ensure efficient exchange of digital tokens without the existence of intermediaries. It can therefore eliminate the inefficient use of labour and create rapid low-cost exchanges. At the same time, such platforms provide the digital infrastructure needed for the development of further innovative applications. For example, blockchains may allow smart contracts 11 to be deployed on them with each smart contract representing an additional application feature. Through smart contracts, blockchain can be connected to outside data collection sources (as proposed in an initiative GainForest, 2019]) e.g., data on forest cover, land-use changes or planting, health, age or the carbon content of trees or forested areas from drones, satellites or on-ground verifiers (presented in Figure 4). Other data concerning legal tenure and social and environmental safeguards could also be included Veridium, 2016. However, to accurately combine various inputs of data, additional types of technology are needed to connect with blockchain, including artificial intelligence (AI) and machine learning techniques, as envisaged in GainForest, 2019, Vlinder, 2019, Pachama, 2020. Their combination can allow to receive decentralised data (from different sources) and using smart algorithms to reach a conclusion on credits' evaluations. If conflicts arise e.g., one data source reports 'yes' and another reports 'no', the system can either assign a higher weight to the more commonly accepted source or request additional data from other sources such as on-ground inspections. The latter option is preferable when multiple entities with conflicted interests report conflicting data, to minimise both the possibility of biased decisions, further conflict and the possibility of collusion regarding the reporting of misleading data. Thus, a hybrid model for data reporting on the evaluation of the veracity of carbon credits is required until the advances of technologies allow humanity to monitor in real-time and accurately supervise the specifics of a REDD + area from anywhere in the world. All token exchanges taking place on blockchain-powered platforms are recorded as immutable and the journey that every token (and accompanying data) follows can be audited from the source to the final destination. Third parties may also audit anyone transacting in these markets. Therefore, any dispute or need for future verification of a transaction can be tracked down and re-confirmed.

The opportunities offered by blockchain technology could become even more attractive by adopting another category of blockchain-based tokens called non-fungible tokens (NFT), which represent digital ownership certificates for unique and specific items - such as a specific tree in a specific location. Using NFTs could allow stakeholders to buy or adopt a particular natural asset, for example, a particular tree from a specific area of forest. Thus, such tokens could be priced differently, since each NFT is backedup with the value of the unique asset, such as the carbon content of the tree. 'Adopt-a-tree' style schemes have mushroomed (for example the Orangutan Project and the Green Initiative Foundation's

\footnotetext{
${ }^{1}$ Smart contracts are publicly available scripts of code that are executed when certain conditions are met. They are ideal for building complex desirable applications on blockchains.
} 
projects in Indonesia and The Nature Conservancy's plans to plant a billion trees) as they give the ability and the motivation for the public to be directly involved in REDD+. The easier the access to these types of schemes, the more increased participation, since engaging with such schemes not only brings citizens closer to nature but also to the local communities where their own natural asset is preserved.

Token-holders in a blockchain system would also have an option to destroy their tokens, mirroring other proposed supply-side interventions in carbon markets such as the retirement of EU ETS allowances by environmental organisations Asproudis and Weyman-Jones, 2020, as well as proposals regarding the purchasing of coal Harstad, 2012, and forests Harstad, 2016. Blockchain can facilitate this process at almost zero transaction costs for environmentally aware stakeholders, who might be willing to buy such tokens offsetting their own carbon footprint and destroying them in order to further contribute to addressing climate change.

\section{Permanence, leakage and additionality}

Smart contracts enabled by blockchain, and used in concert with other modern technologies, such as AI or machine learning could also offer a number of efficient, effective and affordable solutions to help address long-standing issues pertaining to permanence, leakage and additionality that have dogged the development of REDD + projects Palmer, 2011, Atmadja and Verchot, 2012, Chiroleu-Assouline et al., 2018. Permanence is defined by the UNFCCC Special Report on LULUCF as "the longevity of a carbon pool and the stability of its stocks" Watson et al., 2000. Forest carbon is inherently unstable due to the possibility of reversals through either natural processes (disease, forest fire) or human activity (changes in land use practices). This raises the possibility that carbon savings through sequestration, either through afforestration, reforestation or avoided deforestation can be reversed at any point in the future through deforestation or forest degradation, negating the validity of the previously issues carbon credits. The issue is further complicated by the fact that carbon accrues in afforested or reforested areas slowly over time, implying forest projects of this ilk tend to also issue credits slowly and thus require long-term monitoring and verification. The issues associated with these challenges could be mitigated through the use of blockchain technology, in conjecture with AI and machine learning. Updated data on the forested area's status, potentially down to the level of individual trees, could be associated with the token sold to the purchaser of the offset, and should the status of the carbon sequestered change, then the carbon value of the offset could adjust accordingly, or if terms of the smart contract are broken then the credit could be revoked. If the token is sold on, then the relevant information would follow with it along with future changes in the information Treecycle, 2019. The usefulness of blockchain in this area is predicated upon there being suitable, available information from external sources on the status of the forest. The increasing availability of satellite data (e.g. in Brazil [Moutinho, 2021]) along with project level data from drones [Mitchell et al., 2017] would help the deployment of blockchain technologies in this area, but in the short-term the use of the technology is more likely in more developed REDD+ contexts such as Brazil and Indonesia rather than in more challenging environments such as the DRC.

A second issue associated with forestry and REDD+ projects, which could be potentially mit-

igated by use of blockchain technology is leakage. Leakage has been defined as occurring when "interventions to reduce carbon emissions in one place causes carbon emissions in another place" 
Atmadja and Verchot, 2012. In the context of forestry projects, this may occur if land-owners shift deforestation or forest degrading activities to different areas of their land, outside of REDD+ projects, or if the drivers of deforestation shift to different forested areas as a result of the REDD+ intervention. In either case, there will be no overall decrease in emissions as a result of the REDD+ project, merely a geographical shift. Dealing with leakage has been a thorny issue for REDD+ projects, with possible solutions focusing on design options such as buffer zones and nesting project-based approaches within country-level programmes Streck, 2021, Atmadja and Verchot, 2012]. Although the use of blockchain cannot directly solve leakage issues, it could provide a conduit for information pertaining to the problem that would allow for amendments or revocation of credits should the problem become too great. For example, a smart contract could contain a provision that deforestation in a certain buffer zone relating to the project must not rise above a certain threshold, and by capturing and processing this information via AI or similar, blockchain technology could amend or revoke the carbon credit accordingly should this threshold be breached Regen Network, 2018.

The additionality (or not) of emissions reductions from carbon offset projects has been a question raised of projects from all sectors, and in the regulatory and voluntary markets. The concept relates to the question of whether or not the carbon savings or sequestration benefits would have arisen anyway in the absence of the activity or project Valatin et al., 2011. True additionality is ultimately unknowable but tests to approximate the concept have been used across carbon offset projects. In a similar vein to leakage, the use of blockchain cannot eliminate this problem per se - it can, however, provide a tool in capturing relevant information pertaining to additionality (along with AI), process this information and embed it into smart contracts that could validate (or invalidate) the associated carbon credits. For example, along with carrying information about the status of the forested area the blockchain (and smart contract) could also capture, process and communicate information about the prices (and thus profits) of the key drivers of deforestation in the area, whether that be soya, beef, palm oil or gold. If these prices fall below a certain threshold, this could invalidate the additionality of the project and the carbon credit could be adjusted accordingly.

\section{Local communities' involvement and property rights}

With the potential for a decentralized model based on blockchain to reduce transaction costs and to enable financial transparency, local and indigenous communities, in theory, should play much bigger role and thus reap greater benefits from the carbon markets. A number of issues have emerged with various REDD+ projects around the world where the rights of indigenous communities, and others, have been ignored - leaving the community with little or no say whether, and how, foreign activities are affecting their environment and livelihoods [United Nations, 2007. In an effort to deal with this issue, the UN adopted a declaration on IP's rights (UNDRIP), which sets minimum standards of actions to protect the well-being of the indigenous peoples of the world [United Nations, 2007]. However, there is little evidence these standards are considered and an increasing need to design adequate requirements to ensure the adoption of UNDRIP when developing carbon offsets related projects De la Fuente and Hajjar, 2013, Timperley, 2019.

Using technological advances, such standards can be translated and programmed as conditions into smart contracts, so that carbon token transactions within a blockchain-based platform can only take place when these standards are satisfied, ensuring that community rights are upheld. The exact mech- 
anism through which the relevant information would be collated and added to the blockchain would vary between jurisdictions but would likely involve some burden-of-proof on behalf of the organisation selling the REDD+ credits that various provisions regarding property rights are met, including that community rights are upheld and that there are no pre-existing conflicts over the territory.

The use of blockchain in this way on its own cannot resolve the various property rights issue associated with deforestation, and therefore REDD+ projects, including missing, overlapping and heterogeneous property rights. However, it could: $(a)$ ensure that in areas in which such conflicts are occurring, parties with more power cannot exploit communities or other parties with less rights and power; and, (b) incentivise various actors to resolve disputes and conflicts in order to access REDD+ finance, Regen Network, 2018. Blockchain can also add security to buyers that, should such conflicts arise at some future point, the carbon credit would adjust accordingly, potentially removing the validity of the REDD+ credit but also ensuring that no further payments are made and that reputational risks are minimised. Blockchain's advantages in this area are likely to be larger where indigenous and other types of communities' rights are stronger and more established. In areas such as central Africa where local communities' rights have historically been weak [Barrow et al., 2016, the advantages that blockchain may be more on the buyer's side - helping to avoid buying into areas with conflicts and giving them safeguards about future discovery of these conflicts.

For those communities for which property rights are not an issue, a blockchain platform may have an important role in achieving an easier access to buyers in the voluntary carbon market GainForest, 2019, Universal Carbon, 2019, Vlinder, 2019. Local communities could directly sell their climate services through selling tokens to buyers in the voluntary market. By dealing directly with communities, buyers may be able to connect better with potential projects, and help find those that best fit within their various motivations. These aspects could boost private sector demand for REDD+ credits.

The use of simple, reliable, cheap online platforms also creates opportunities for communities to promote and sell other products Veridium, 2016, Grove (FSL), 2020, Vlinder, 2019, therefore enabling cross selling locally and globally. In addition, multiple blockchain-powered platforms under development Universal Carbon, 2019 aim to allow for the exchange of carbon tokens with other cryptocurrencies' tokens. Thus, once communities are established as active participants in these markets, they could also access other related forms of investment, e.g. cryptocurrencies or other token-trading schemes.

A potential question-mark over the viability of the establishment of a blockchain platform for REDD + credits is the capacity of local communities to engage in such a platform and the associated technology. However, there is evidence from a number of countries and projects that rural farmers, small-holders and indigenous communities have the capacity to engage in technologies such as blockchain through devices such as smartphones and reap the multiple benefits offered by blockchainbased carbon markets. For example, in the North Rupununi region of Guyana, there was established a Community-Based Monitoring (CBM) System for REDD+ that required members of local communities to utilise GPS and ODK software on mobile phones to track forest clearance with evaluations of the system - highlighting the capacity of the communities involved Bellfield et al., 2015. Projects such as Rainforest Foundation's MappingForRights initiative also demonstrate this capacity, with communities in the DRC using software and GPS-enabled tablets to map customary lands and resources 
Handja, 2014. These examples highlight that many communities either have sufficient capacity, or could develop the relevant capacity with suitable assistance. What is more likely to be a barrier for the development of a blockchain-related platform is the availability of suitable technology and infrastructure.

\section{Discussion}

Blockchain technologies are already emerging in REDD+ projects, in proposals and pilots. Due to its decentralised and transparent nature, blockchain could enforce verifiable smart contracts as well as providing systems for reducing transaction costs and enabling reduced monitoring and verification costs - a potentially promising solution for expanding REDD+ beyond current levels.

Despite its potential, concerns remain relating to REDD+ which cannot be directly tackled by existing blockchain technologies. These include the pervasive additionality issue, along with leakage - although the technology could play a role in at least providing information on the situation. Even more challenging is likely to be property rights - often a major driver in deforestation itself Cotula and Mayers, 2009, Palmer et al., 2010. Blockchain for REDD+ is only likely to be effective in geographies where property rights are clear and conflicts are absent. However, the technology could help in providing assurance to buyers of credits that rights issues are resolved and indigenous rights are upheld along with providing incentives for the resolution of rights conflicts. The fact that the benefits of blockchain may not accrue to communities involved in rights disputes, where perhaps the benefits of REDD + finance may be of most use, is a downside to the use of technology - with further research needed to examine how emerging technologies can assist into this.

A critical area for further analysis is the pre-conditions needed for the emergence of blockchain for REDD+. This may include the resolution of rights, but also suitable capacity relating to technology - both availability and application. Existing REDD+ activities highlight that suitable capacity to use technology can exist in rural and indigenous communities. However, larger barriers are likely to be the availability of appropriate technology, and measurement and monitoring capacity in remote areas. Building this capacity, along with the suitable technology architecture is likely to be vital in developing strong, effective blockchain-related REDD+ projects.

Utilising blockchain for REDD+ may also bring complimentary benefits to the development, and marketing of sustainable products and supply chains. This has not been the focus of this paper but the ability for information pertaining to emissions, carbon content, and how appropriate offsetting to accompany physical products via blockchain potentially addresses a number of challenges in this area. Yet it requires further research. What is needed is an in-depth assessment of the early experience of project developers utilising blockchain for REDD + to understand the extent to which the technology has actually managed to overcome fundamental issues that have plagued REDD + . The results from such assessment should then feed into analysis of the role that blockchain could play in the wider voluntary carbon market. This is particularly important as blockchain is evolving, and new technologies are proving to be more energy efficient, faster and more scalable than their predecessors. It is clear that as these technologies become increasingly mainstream future research needs to focus on how to ensure that project developers will utilise them to widen market participation, reduce transaction costs, engender demand, and address issues of efficiency, equity and effectiveness. 


\section{Conclusion}

Blockchain technologies are entering the climate change space, and particularly REDD+ projects, for good or for bad, at the same time that the demand for voluntary carbon offsets is projected to boom. Blockchain is being used by developers to overcome issues of engagement, monitoring, transparency and demand. The open, and crucial, question is how effective can this technology be at overcoming issues such as transaction costs, permanence, additionality, leakage and property and community rights that have limited the growth and effectiveness of REDD + to date. In this paper we examine the technology, how it is used so far and highlight that blockchain has the potential to help to overcome challenges such as transaction costs, and, in combination with other technology, dealing with permanence and additionality. Evidence from other areas highlights that local communities are likely to have, or could be aided to have, the capacity to utilise the technology. The use of the technology is however likely to be hindered in areas where infrastructure is limited and where issues around property rights remain. What is needed now is an ongoing evaluation of the emerging use of blockchain in REDD+ projects in collaboration with developers to build an evidence base of its effectiveness and to strengthen recommendations for improvements in its use.

\section{Acknowledgements}

We thank Professor Luitgard Veraart for a fruitful discussion and her valuable feedback comments. We also thank Craig Stock for valuable research assistance with data visualization.

\section{References}

[A Angelsen, 2010] A Angelsen (2010). The 3 REDD "i"s. Journal of Forest Economics, (16):253-256.

[Asproudis and Weyman-Jones, 2020] Asproudis, E. and Weyman-Jones, T. (2020). How the engos can fight the industrial/business lobby with their tools from their own field? engos participation in emissions trading market. Sustainability, 12(20):8553.

[Atmadja and Verchot, 2012] Atmadja, S. and Verchot, L. (2012). A review of the state of research, policies and strategies in addressing leakage from reducing emissions from deforestation and forest degradation (redd+). Mitigation and Adaptation Strategies for Global Change, 17(3):311-336.

[Barrow et al., 2016] Barrow, E., Kamugisha-Ruhombe, J., Nhantumbo, I., Oyono, R., and Savadogo, M. (2016). Who owns africa's forests? exploring the impacts of forest tenure reform on forest ecosystems and livelihoods. Forests, trees and livelihoods, 25(2):132-156.

[Bellfield et al., 2015] Bellfield, H., Sabogal, D., Goodman, L., and Leggett, M. (2015). Case study report: Community-based monitoring systems for redd+ in guyana. Forests, 6(1):133-156.

[BiTA, 2017] BiTA (2017). Bita: Blockchain in transport alliance. https://www.bita.studio/.

[BP, 2020] BP (2020). Bp sets ambition for net zero by 2050, fundamentally changing organisation to deliver. pages https://www.bp.com/en/global/corporate/news-and-insights/pressreleases/bernard-looney-announces-new-ambition-for-bp.html. 
[Broadbridge, 2018] Broadbridge (2018). Next-generation proxy voting: How data-driven analytics, omni-channel delivery and blockchain are helping mutual funds achieve their proxy goals. broadbridge.com.

[Carbon Credit Token, 2020] Carbon Credit Token (2020). Carbon credit mco2 token. mco2token. moss.earth. Accessed: July 2021.

[Chen, 2018] Chen, D. (2018). Utility of the blockchain for climate mitigation. The Journal of The British Blockchain Association, 1(1):3577.

[Chiroleu-Assouline et al., 2018] Chiroleu-Assouline, M., Poudou, J.-C., and Roussel, S. (2018). Designing redd+ contracts to resolve additionality issues. Resource and Energy Economics, 51:1-17.

[Cotula and Mayers, 2009] Cotula, L. and Mayers, J. (2009). Tenure in REDD: Start-point or Afterthought? Number 15. IIED.

[De la Fuente and Hajjar, 2013] De la Fuente, T. and Hajjar, R. (2013). Do current forest carbon standards include adequate requirements to ensure indigenous peoples' rights in redd projects?

[de Pee et al., 2018] de Pee, A., Pinner, D., Roelofsen, O., Somers, K., Speelman, E., and Witteveen, M. (2018). Decarbonization of industrial sectors: the next frontier. McKinsey Sustainability Report, page McKinsey \& Company.

[Eliasch, 2012] Eliasch, J. (2012). Climate change: financing global forests: the Eliasch review. Routledge.

[EU, 2019] EU (2019). Text adopted - climate change - thursday, 14 march 2019. (assessed 14.06.2021):https://www.europarl.europa.eu/doceo/document/TA-8-2019-0217 ${ }_{E}$ N.html.

[Facebook, 2019] Facebook (2019). Our climate commitment - facebook sustainability. (assessed 14.06.2021):https://sustainability.fb.com/our-climate-commitment/.

[GainForest, 2019] GainForest (2019). Gainforest: A sustainable smart contract for our natural world. gainforest.app. Accessed: July 2021.

[Google, 2020] Google (2020). 24/7 by 2030: Realizing a carbon-free future.

[Grove (FSL), 2020] Grove (FSL) (2020). Grove: Forestry smart ledger. bit.1y/3wxJ08i. Accessed: July 2021.

[Handja, 2014] Handja, G. T. (2014). Mappingforrights: An initiative of the rfuk and his partners in the congo basin. In Land grabbing, Land Rights and Human Rights:(Re) Setting the Agenda seminar. University of East London, Centre for Human Rights in Conflict.

[Harstad, 2012] Harstad, B. (2012). Buy coal! a case for supply-sde enviornmental policy. Journal of Political Economy, 120(1):77-115.

[Harstad, 2016] Harstad, B. (2016). The market for conservation and other hostages. Journal of Economic Theory, 166:124-151. 
[Hartmann and Thomas, 2020] Hartmann, S. and Thomas, S. (2020). Applying blockchain to the australian carbon market. Economic Papers: A journal of applied economics and policy, 39(2):133-151.

[Howson, 2019] Howson, P. (2019). Tackling climate change with blockchain. Nature Climate Change, $9(9): 644-645$.

[Howson et al., 2019] Howson, P., Oakes, S., Baynham-Herd, Z., and Swords, J. (2019). Cryptocarbon: the promises and pitfalls of forest protection on a blockchain. Geoforum, 100:1-9.

[IRENA, 2019] IRENA (2019). Blockchain innovation landscape brief. IRENA: International Renewable Energy Agency.

[Laing et al., 2016] Laing, T., Taschini, L., and Palmer, C. (2016). Understanding the demand for redd+ credits. Environmental Conservation, 43(4):389-396.

[Maguire, 2011] Maguire, R. (2011). Opportunities for forest finance: Compliance and voluntary markets. Climate and Carbon Law Review, (1):100-112.

[McKinsey, 2020] McKinsey (2020). How covid-19 has pushed companies over the technoloyg tipping point - and transformed business foreover. McKinsey Digital and Strategy 8 Corporate Finance Practices.

[Metelitsa, 2018] Metelitsa, C. (2018). A snapshot into blockchain deployment and investments in the power sector. Wood Mackenzie Power \& Renewables.

[Mitchell et al., 2017] Mitchell, A. L., Rosenqvist, A., and Mora, B. (2017). Current remote sensing approaches to monitoring forest degradation in support of countries measurement, reporting and verification (mrv) systems for redd+. Carbon balance and management, 12(1):1-22.

[Moutinho, 2021] Moutinho, S. (2021). First brazilian-made satellite watches the amazon.

[Nantongo and Vatn, 2019] Nantongo, M. and Vatn, A. (2019). Estimating transaction costs of redd+. Ecological economics, 156:1-11.

[Nation, 2021] Nation, U. (2021). United nation framework convention on climate change (unfccc). n.d. REDD+ Web Platform.

[Nestle, 2019] Nestle (2019). Our road to net zero. pages https://www.nestle.com/csv/globalinitiatives/zero-environmental-impact/climate-change-net-zero-roadmap.

[NGFS, 2021] NGFS (2021). Ngfs climate scenarios for central banks and supervisors. Network for Greening the Financial System, June.

[Nori, 2017] Nori (2017). Nori - a blockchain-based marketplace for removing carbon dioxide from the atmosphere. nori.com/token. Accessed: July 2021.

[Oberhauser, 2019] Oberhauser, D. (2019). Blockchain for environmental governance: Can smart contracts reinforce payments for ecosystem services in namibia? Frontiers in Blockchain, 2. 
[Pachama, 2020] Pachama (2020). Remove carbon. restore forests. harnessing ai to drive carbon capture and protect global forests. pachama.com. Accessed: July 2021.

[Palmer, 2011] Palmer, C. (2011). Property rights and liability for deforestation under redd+: Implications for 'permanence'in policy design. Ecological economics, 70(4):571-576.

[Palmer et al., 2010] Palmer, C. et al. (2010). Redd+: Property rights and liability. Science (Washington), 328(5982).

[Regen Network, 2018] Regen Network (2018). Regen network whitepaper. regen.network. Accessed: July 2021.

[Rogelj et al., 2018] Rogelj, J., Shindell, D., Jiang, K., Fifita, S., Forster, P., Ginzburg, V., Handa, C., Kheshgi, H., Kobayashi, S., Kriegler, E., Mundaca, L., Sfrian, R., and M.V.Vilario (2018). Mitigation pathways compatible with $1.5 \mathrm{c}$ in the context of sustainable development. In Masson-Delmotte, V., Zhai, P., Prtner, H.-O., Roberts, D., Skea, J., Shukla, P., Pirani, A., Moufouma-Okia, W., Pan, C., Pidcock, R., Connors, S., Matthews, J., Chen, Y., Zhou, X., Gomis, M., Lonnoy, E., Maycock, T., Tignor, M., and Watefield, T., editors, Global Warming of 1.5C. An IPCC Special Report on the impacts of global warming of $1.5 \mathrm{C}$ above pre-industrial levels and related global greenhouse gas emission pathways, in the context of strengthening the global response to the threat of climate change, sustainable development, and efforts to eradicate poverty.

[Shankleman and Rathi, 2021] Shankleman, J. and Rathi, A. (2021). Wall street's favorite climate solution is mired in disagreements. Bloomberg Green, June 2.

[Streck, 2020] Streck, C. (2020). Who owns redd+? carbon markets, carbon rights and entitlements to redd+ finance. Forests, 11(9):959.

[Streck, 2021] Streck, C. (2021). Redd+ and leakage: debunking myths and promoting integrated solutions. Climate Policy, pages 1-10.

[Timperley, 2019] Timperley, J. (2019). Carbon offsets have patchy human rights record. now un talks erode safeguards. https://bit.1y/3ieT2W8. Accessed: July 2021.

[Treecycle, 2019] Treecycle (2019). Treecoin. https://treecycle.ch/. Accessed: July 2021.

[TSVCM, 2020a] TSVCM (2020a). Consultation document. Taskforce on Scaling Voluntary Carbon Markets (TSVCM).

[TSVCM, 2020b] TSVCM (2020b). Consultation document, by the Taskforce on Scaling Voluntary Carbon Markets, Institute of International Finance.

[UK, 2021] UK (2021). Uk enshrines new target in law to slash emissions by $78 \%$ by 2035 gov.uk. (assessed 14.06.2021):https://www.gov.uk/government/news/uk-enshrines-new-target-inlaw-to-slash-emissions-by-78-by-2035.

[UNFCC, 2021] UNFCC (2021). New financial alliance for net zero emissions launches. External Press Release, 21 April, 2021:https://unfccc.int/news/new-financial-alliance-for-net-zero-emissionslaunches. 
[United Nations, 2007] United Nations (2007). United nations declaration on the rights of indigenous peoples. Adopted 107th plenary meeting 13 September 2007.

[Universal Carbon, 2019] Universal Carbon (2019). The clean crypto: Introducing the world's first tradable carbon token. universalcarbon.com. Accessed: July 2021.

[US, 2021] US (2021). U.s. officially rejoins paris agreement on climate change : Npr. (assessed 14.06.2021):https://www.npr.org/2021/02/19/969387323/u-s-officially-rejoins-paris-agreement-onclimate-change.

[Valatin et al., 2011] Valatin, G. et al. (2011). Forests and carbon: a review of additionality. Number 013. Forestry Commission.

[Veridium, 2016] Veridium (2016). Unlocking the world's environmental asset market. veridium.io. Accessed: July 2021.

[Vlinder, 2019] Vlinder (2019). Future matters: An impact-tech platform for sustainanle investing and direct carbon credits purchasing. vlinderclimate.com. Accessed: July 2021.

[Watson et al., 2000] Watson, R. T., Noble, I. R., Bolin, B., Ravindranath, N., Verardo, D. J., Dokken, D. J., et al. (2000). Land use, land-use change and forestry: a special report of the Intergovernmental Panel on Climate Change. Cambridge University Press. 


\section{Appendix}

Figure 5: A Blockchain Network

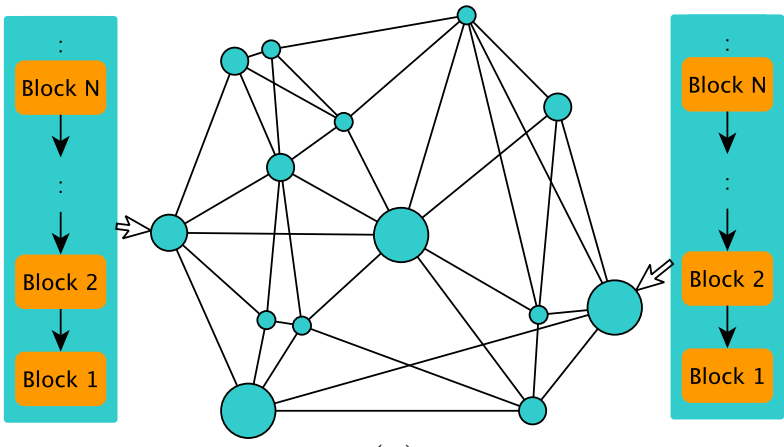

$(a)$

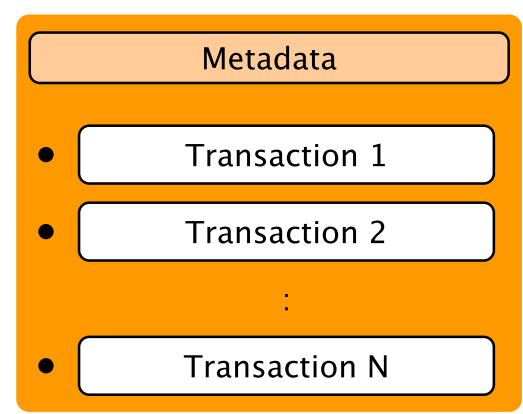

(b)

(a) Each node communicates with others to decide on which of the received transaction data is valid and therefore permanently stored in the ledger. These node decisions are strictly based on a pre-defined set of rules (known as consensus protocol) that describe how nodes can reach an agreement on this issue. When a node within a blockchain network receives new transaction data, the general procedural steps are as follows: if the node believes this data is valid, it is then shared across the network and, if all nodes agree (following the preset consensus protocol), data is immutably stored in the ledger. (b) Multiple confirmed and valid pieces of transaction data are first formed into groups (known as blocks) and then recorded in an "append only" manner, e.g. a new block is linked only to the previously recorded block. The sequential linking of blocks requires advanced techniques of cryptography, so that every link in the chain demonstrates a secure bond (stored in the metadata section) among each two blocks. Hence, blocks eventually form an ordered immutable chain of recorded data, a blockchain [?, ?]. Once a new block is added onto the blockchain, every other node receives a copy of the updated blockchain. 